\title{
In Vivo Selectivity and Localization of Reactive Oxygen Species (ROS) Induction by Osmium Anticancer Complexes That Circumvent Platinum Resistance
}

\author{
James P. C. Coverdale, ${ }^{\dagger}$ Hannah E. Bridgewater, ${ }^{\dagger}$ Ji-Inn Song, $^{\dagger}$ Nichola A. Smith, ${ }^{\dagger}$

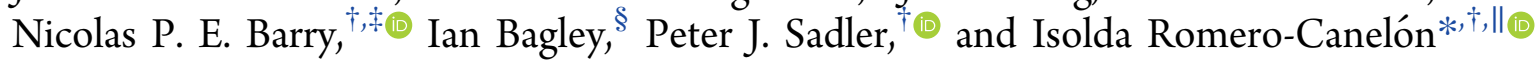 \\ ${ }^{\dagger}$ Department of Chemistry, University of Warwick, Coventry CV4 7AL, U.K. \\ ${ }^{\ddagger}$ School of Chemistry and Biosciences, University of Bradford, Bradford BD7 1DP, U.K. \\ ${ }^{\S}$ BSU Research Technology Platform, University of Warwick, Coventry CV4 7AL, U.K. \\ "School of Pharmacy, University of Birmingham, Birmingham B15 2TT, U.K.
}

Supporting Information

\begin{abstract}
Platinum drugs are widely used for cancer treatment. Other precious metals are promising, but their clinical progress depends on achieving different mechanisms of action to overcome Pt-resistance. Here, we evaluate 13 organo-Os complexes: 16-electron sulfonyl-diamine catalysts $\left[\left(\eta^{6}\right.\right.$-arene $\left.) \operatorname{Os}\left(N, N^{\prime}\right)\right]$, and 18-electron phenylazopyridine complexes $\left[\left(\eta^{6} \text {-arene }\right) \mathrm{Os}\left(N, N^{\prime}\right) \mathrm{Cl} / \mathrm{I}\right]^{+}$(arene $=p$-cymene, biphenyl, or terphenyl). Their antiproliferative activity does not depend on $p 21$ or $p 53$ status, unlike cisplatin, and their selective potency toward cancer cells involves the generation of reactive oxygen species. Evidence of such a mechanism of

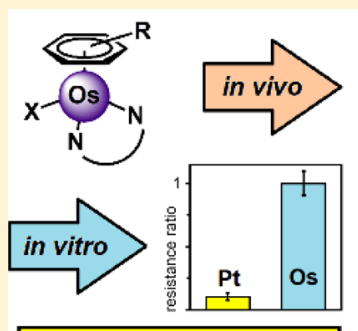

Overcome Pt resistance

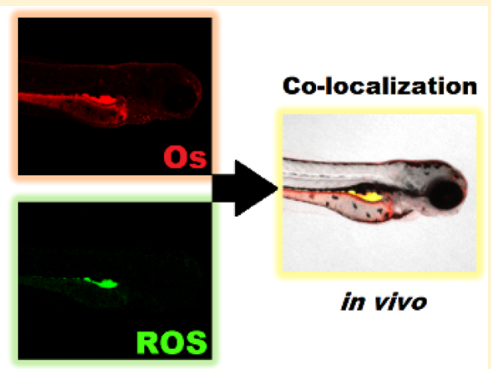

ROS action has been found both in vitro and in vivo. This work appears to provide the first study of osmium complexes in the zebrafish model, which has been shown to closely model toxicity in humans. A fluorescent osmium complex, derived from a lead compound, was employed to confirm internalization of the complex, visualize in vivo distribution, and confirm colocalization with reactive oxygen species generated in zebrafish.
\end{abstract}

\section{INTRODUCTION}

Cancer is one of the leading causes of death in the developed world. ${ }^{1,2}$ As many as half of all cancer chemotherapy regimens include a platinum drug, which typically targets DNA, and is either administered alone or in combination therapies. ${ }^{3}$ However, both intrinsic and acquired Pt-resistances are major clinical concerns, ${ }^{4-6}$ requiring the development of drugs that circumvent this problem by possessing an alternative-or multitargeted-mechanism of action (MoA). Other precious metals have promising anticancer activity, including organo-Os (complexes that, unlike cisplatin, do not have DNA as their major target). Specifically, some Os(II) "piano-stool" (metal-arene "half-sandwich") complexes have been shown to exhibit nanomolar potency against cancer cells ${ }^{7}$ and yet also low in vivo toxicities. ${ }^{8}$ The "piano-stool" structure of such complexes allows medicinal chemists to fine-tune the biological properties of the complex by careful manipulation of coordinated ligands, resulting in a wide range of different cellular mechanism(s) of action, not limited to redox modulation (both oxidative and reductive stress), ${ }^{9,10}$ DNA binding, or protein kinase inhibition. ${ }^{11}$ Higher oxidation state complexes of osmium also show clinical promise, with potential both in vitro and in vivo. ${ }^{12}$ The mechanism of action of Os(VI) nitrido complexes developed by Lippard et al. depends greatly on the choice of ligands; structurally similar complexes activate either $p 53$-dependent or $p 53$-independent cell death pathways, depending on the nature of the coordinated ligands. ${ }^{13}$

We have previously reported two interesting classes of osmium(II) arene anticancer complexes with different chemical properties: osmium-sulfonamide transfer hydrogenation catalysts, which can convert pyruvate to lactate in cells, $^{10}$ and highly potent osmium-azopyridine complexes, which generate reactive oxygen species (ROS) in cancer cells. ${ }^{7,14}$ Intrinsic levels of ROS are frequently elevated in cancer cells, typically arising from mitochondrial dysfunction and the higher metabolic activity associated with tumor proliferation and metastasis. ${ }^{15}$ However, further oxidative stress is known to cause cell cycle arrest and apoptosis, ${ }^{16-19}$ which therefore presents a novel chemotherapeutic target that could render selectivity toward cancer cells. ${ }^{20}$ In this work, we compare the antiproliferative activity of these previously reported classes of Os(II) compounds, ${ }^{10,21}$ their ability to

Received: June 15, 2018

Published: September 19, 2018 
generate reactive oxygen species (ROS) in both cancer cells and in vivo, as well as their remarkable selectivity and potential for circumventing Pt-resistance.

The 16e Os(II) arene sulfonamide transfer hydrogenation catalysts $\mathbf{1 - 8}$ can convert pyruvate to lactate in cells. ${ }^{10}$ The highly potent $18 \mathrm{e}$ azopyridine complexes are much less reactive (especially the relatively inert iodido complexes) and appear to be activated inside cells and target mitochondria. ${ }^{14,21} \mathrm{We}$ have compared the potency and selectivity of these two classes of complexes toward cells in culture and their in vivo toxicity in zebrafish (Danio rerio) embryos as a high-throughput vertebrate model, ${ }^{22,23}$ considered to be a predictor for drug toxicity in humans. ${ }^{24-26}$ Unlike rodent models, zebrafish embryos are easy to handle, inexpensive, and useful for the study of solubilized compounds without consideration required for formulation or route of delivery. We investigated the MoA of the osmium(II) complexes in 2D cell culture and show how it translates into the in vivo zebrafish model. The zebrafish genome has been sequenced, and $c a .75 \%$ of human genes have at least one zebrafish orthologue. ${ }^{26}$ Zebrafish embryos share developmental phenotypes with mammals, and many biochemical pathways are conserved. ${ }^{27}$ In fact, zebrafish have been used to identify cell cycle inhibitors ${ }^{28}$ and compounds that activate the p53 pathway, inducing apoptosis. ${ }^{29}$ Furthermore, the correlation between cardiotoxicity and hepato-toxicity in zebrafish and preclinical mammalian models is well established. ${ }^{30}$ Toxicity studies of $\mathrm{Ru}(\mathrm{II})$ and $\operatorname{Ir}(\mathrm{III})$ complexes in zebrafish have been reported, ${ }^{31-34}$ but this study appears to be the first on Os(II) complexes. We have synthesized a fluorescently labeled complex that has enabled the in vivo biodistribution of Os to be compared with the site(s) of ROS generation. This work reveals the critical roles of the ligands in determining the anticancer potency of complexes including their mechanism of action, toxicity, and selectivity and has allowed identification of complexes with potential for clinical development. Specifically, we investigate the translation of the mechanism of action and accumulation of Os(II) arene complexes from in vitro cellular studies to a readily available in vivo model.

\section{RESULTS}

Sulfonamide complexes $\mathbf{1 - 5}$ and $7-8$ and azopyridine complexes 9-13 (Scheme 1) have been previously reported and are known to be stable in aqueous media. ${ }^{10,21}$ In addition, a novel rhodamine-conjugated sulfonamide-diphenyl-ethylenediamine ligand L6 was synthesized by the reaction between rhodamine sulfonyl chloride and the chiral diamine (see Supporting Information). Complex 6, containing ligand L6, was synthesized as a dark purple solid in a biphasic reaction (dichloromethane/water) with the dimer $\left[\left(\eta^{6}-p\right.\right.$-cymene $)$ $\left.\mathrm{OsCl}_{2}\right]_{2}$ and a base (potassium hydroxide), yielding a dark purple solid.

In Vitro Antiproliferative Activity. Antiproliferative activities $\left(\mathrm{IC}_{50}\right.$ values, concentrations that inhibit $50 \%$ of cell growth) toward nine human cell lines were determined for complexes 1-13 by investigating cell viability after drug exposure $(24 \mathrm{~h}+72 \mathrm{~h}$ recovery time $)$ using the SRB assay, and compared to the anticancer drug, cisplatin. The nature of the $\mathrm{N}, \mathrm{N}$-bidentate ligand is crucial to the anticancer activity in three parental cancer cell lines, A2780 (ovarian), A549 (lung), and HCT116 (colon), as can be seen in Tables S1 and S2. Sulfonamide complexes $\mathbf{1 - 8}$ have lower antiproliferative activity compared to cisplatin $\left(\mathrm{IC}_{50} 4.4-30 \mu \mathrm{M}\right.$ in $\mathrm{A} 2780$,
Scheme 1. Osmium(II) Sulfonamide Complexes 1-8 and Azopyridine Complexes 9-13 Studied in This work ( $p$-cym = para-Cymene)

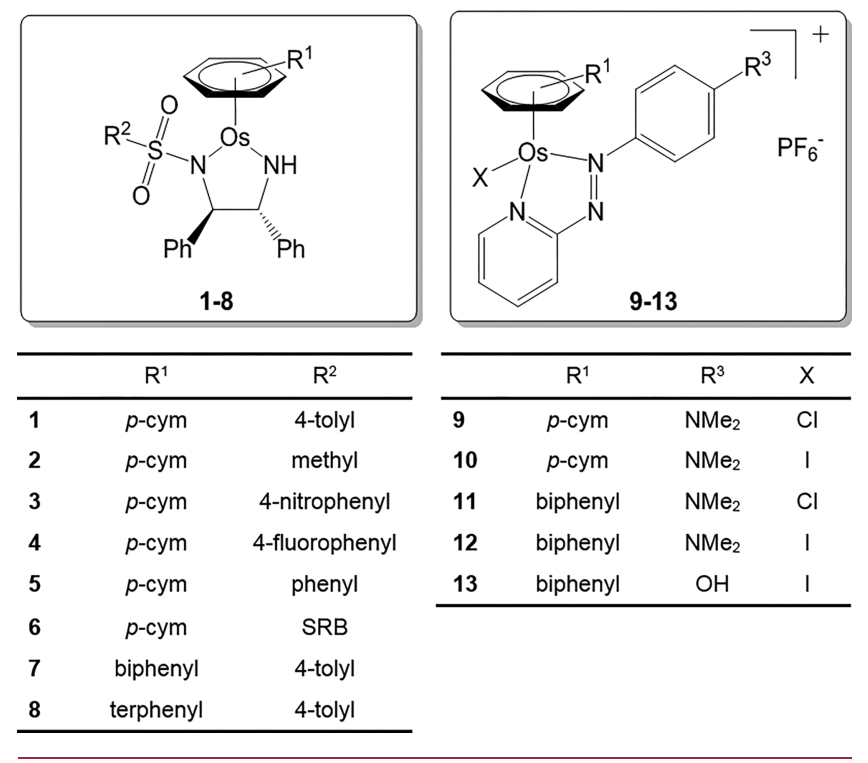

compared to $1.2 \mu \mathrm{M}$ for cisplatin), while azopyridine complexes 9-13 were highly potent, achieving, in some cases, nanomolar potency ( $\mathrm{IC}_{50} 140 \mathrm{nM}$ for 13 in A2780). Generally, both series of Os(II) arene complexes were most potent toward A2780 ovarian cancer cells and least potent toward HCT116 colon cancer cells (Figure 1a, Table S1).

The $\eta^{6}$-arene also influences the antiproliferative properties of the complexes, with higher activities achieved upon arene extension ( $p$-cymene $<$ biphenyl $<m$-terphenyl) in both the sulfonamide $(2<7<8)$ and azopyridine $(9<11 ; 10<12)$ series. This is probably due to increased hydrophobicity, although this does not always translate directly to increased cellular accumulation and improved anticancer potency since uptake mechanisms can involve active/energy-dependent pathways as well as passive diffusion. Nonetheless, the observed trend has been noted previously for other $N, N^{\prime}$ chelated Os(II) arene "piano-stool" complexes. ${ }^{35}$ Furthermore, exchange of $\mathrm{Cl}$ for I in piano-stool azopyridine complexes 913 further enhanced the potency $(9<10 ; 11<12)$, in some cases by nearly 2 orders of magnitude (in A549 cells: complex 11, $\mathrm{IC}_{50} 20 \pm 1 \mu \mathrm{M}$, compared to $12, \mathrm{IC}_{50} 0.27 \pm 0.03 \mu \mathrm{M}$ ). Since halide exchange can modify cellular uptake and accumulation pathways involved in the first stages of drug action, ${ }^{36}$ such a potency increase by halide exchange may be attributed to the triggering of different apoptotic pathways as a consequence of differential compartmentalization and/or target recognition of the complexes once they have reached intracellular space. ${ }^{37}$ Previous reports show that complex 1 accumulates in the cytoplasm, ${ }^{10}$ while complex $\mathbf{1 0}$ locates in mitochondria. ${ }^{38}$

In the clinic, ovarian cancers are commonly treated with platinum complexes; ${ }^{39}$ however, both intrinsic and acquired resistance mechanisms reduce the efficacy of platinum therapies. The ability of Os(II) arene complexes to circumvent Pt resistance mechanisms and maintain activity in Pt-resistant cell lines was first investigated using A2780 Cis (cisplatinresistant) cancer cells. Resistance factors were determined as the ratio between $\mathrm{IC}_{50}$ values for Pt-resistant cells and parental cells (Figure 1b, Table S2), which provide an indication as to 


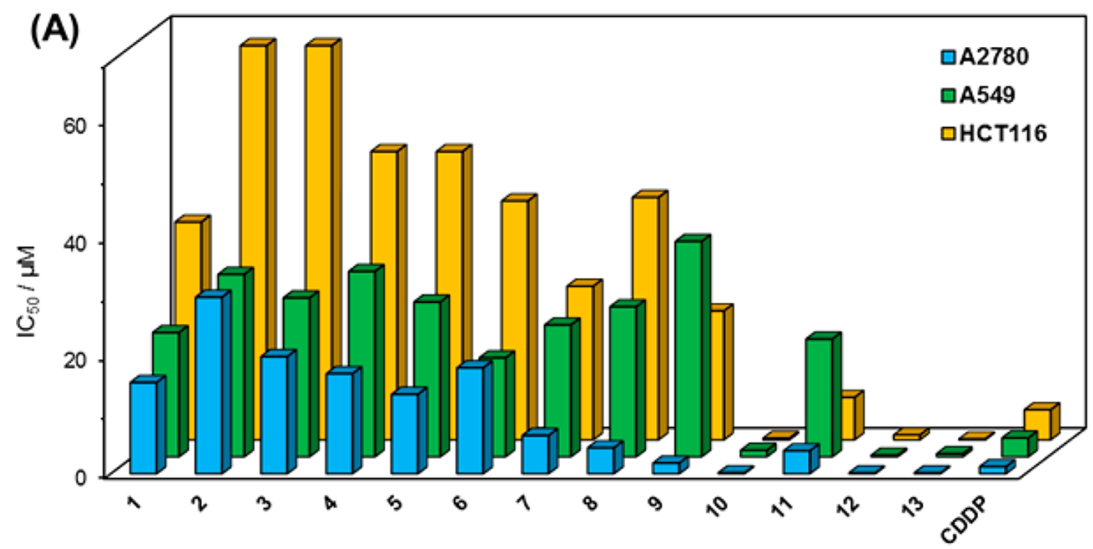

(B)

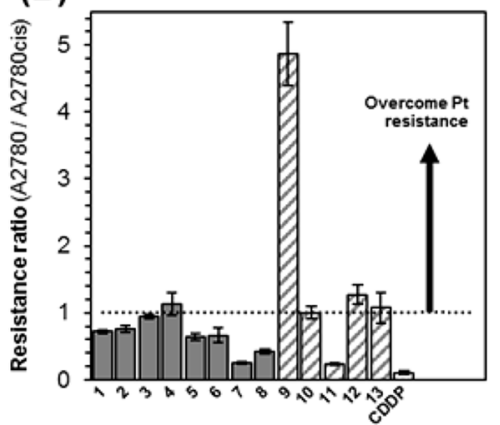

(C)

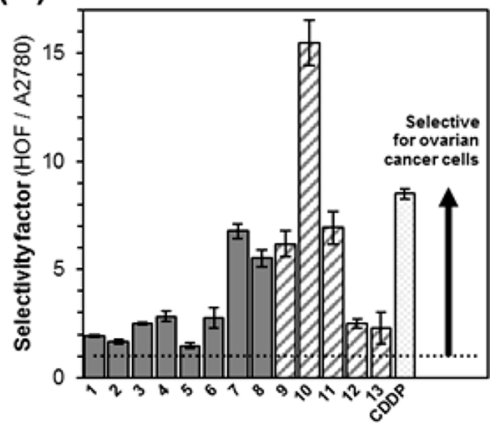

Figure 1. Half-maximal inhibitory concentrations $\left(\mathrm{IC}_{50}, \mu \mathrm{M}\right)$ for $\mathrm{Os}(\mathrm{II})$ complexes 1-13 and cisplatin (CDDP). (a) IC (D0 $_{50}$ values for 1-13 span 2 orders of magnitude; highest activity is toward A2780 ovarian carcinoma (blue) compared to A549 lung carcinoma (green) and HCT116 colorectal carcinoma (yellow) cells. (b) Os(II) arene complexes can overcome Pt-resistance. Resistance ratios for complexes 1-13 and CDDP (IC 50 in A2780/IC 50 in A2780cis cisplatin-resistant cells). Azopyridine complexes 9-13 (striped) show particular promise for overcoming Pt-resistance in ovarian cancer cells. (c) Os(II) arene complexes are selective for A2780 ovarian cancer cells over noncancerous HOF healthy ovarian fibroblasts $\left(\mathrm{IC}_{50}\right.$ in $\mathrm{HOF} / \mathrm{IC}_{50}$ in A2780). See Tables S1 and S2 for full numerical data.

whether it is possible for a given complex to maintain its potency in the platinum-resistant cell line. No reduction in potency was observed for any of the azopyridine complexes 913 in the Pt-resistant cell line, with the exception of chlorido complex $11(3.9 \pm 0.3 \mu \mathrm{M}$ in A2780, $16.8 \pm 0.2 \mu \mathrm{M}$ in $\mathrm{A} 2780$ Cis). In the sulfonamide series, only complexes 3 and 4 maintained their antiproliferative potency in the Pt-resistant cell line (Figure 1b), showing that the nature of the $N, N$ chelating ligand, arene, and halide ligand all contribute to the overall biological properties of the complex. Azopyridine complexes 9-13 may have different uptake and efflux pathways compared to cisplatin and a mechanism of action that is not DNA-based. ${ }^{14}$

Further insights into the behavior of these Os(II) complexes at the cellular level can be gained by determination of osmium accumulation in the presence or absence of verapamil, a compound known to inhibit the transporter P-glycoprotein $(\mathrm{PgP})$, which is associated with multidrug-resistant cells. ${ }^{40}$ Complex 1 appeared to undergo detoxification by PgPpromoted cellular efflux $(P<0.05)$, as well as complex 10 but to a lesser extent (see Supporting Information). This demonstrates how the bidentate ligand can affect cellular accumulation via biochemical interactions experienced by metal complexes in cells.

Pt-resistance at the cellular level is also related to the presence/absence of mutations in particular oncogenes, such as p21 and p53. Maintaining anticancer activity in cells with such mutations is particularly important since they are present in ca. $50 \%$ of cancers. ${ }^{41}$ The dependence of activity on the tumor suppressor $P 53$ was investigated using HCT116p53-/(P53 knockout) cancer cells (Table S2). While the P53 status affected some of the antiproliferative activities of the osmium complexes, the activity of some osmium azopyridine complexes was unaffected (complex 13: $0.15 \pm 0.01 \mu \mathrm{M}$ in the parental HCT116 cell line, compared to $0.13 \pm 0.01 \mu \mathrm{M}$ in p53-/cells). For many of the azopyridine complexes, the significance was minor when compared to Pt drugs; cisplatin was almost an order of magnitude less active $(36.7 \mu \mathrm{M})$ in the P53 knockout cell line. Similarly, dependence of activity on the tumor suppressor P21 was investigated in HCT116p21-/- (P21 knockout) cancer cells (Table S2). All complexes investigated (1-13 and cisplatin) showed lower activities in the P21 knockout cell line. Interestingly, in the case of HCT116Ox (oxaliplatin-resistant) colorectal cancer cells, both sulfonamide and azopyridine complexes all appeared to overcome Ptresistance. In contrast, cisplatin was $4.5 \times$ less active in the Ptresistant line. However, all osmium complexes were typically less active against the colorectal cancer cells (Figure 1a).

Antiproliferative activities in ovarian (A2780) and lung (A549) parental cancer cell lines were compared to data obtained in primary ovarian (HOF) and lung (MRC5) fibroblasts, models for noncancerous cells. Ratios between the anticancer activities in normal cells and cancer cells often provide an early indication of the possible therapeutic window for a given developmental drug, and the values are particularly relevant when compared to those of standards of care medications determined under the same experimental conditions. All Os(II) complexes typically showed good 
Untreated

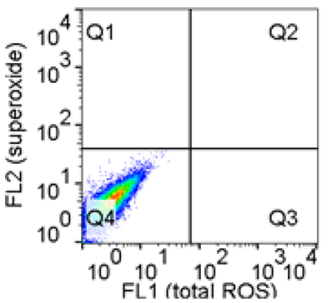

Complex 1

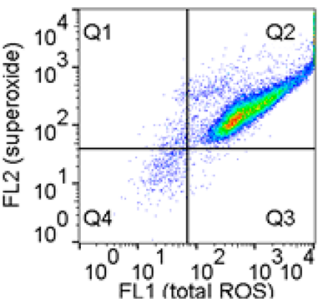

Complex 10

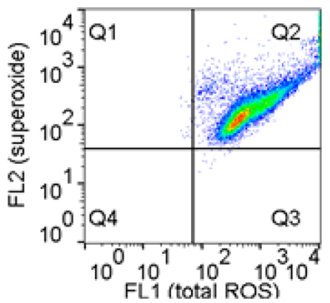

Figure 2. Detection of reactive oxygen species (ROS) by flow cytometry in A2780 cancer cells treated with Os-sulfonamide 1 or Os-azopyridine 10 for $24 \mathrm{~h}\left(1 \times \mathrm{IC}_{50}\right)$ compared to untreated control. FL1 channel, total ROS (including hydrogen peroxide, hydroxyl-radicals and nitro-radicals); FL2 channel, superoxide. See SI for full numerical data.

(a)

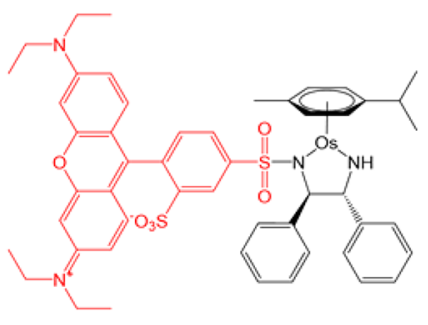

Complex 6

(b)

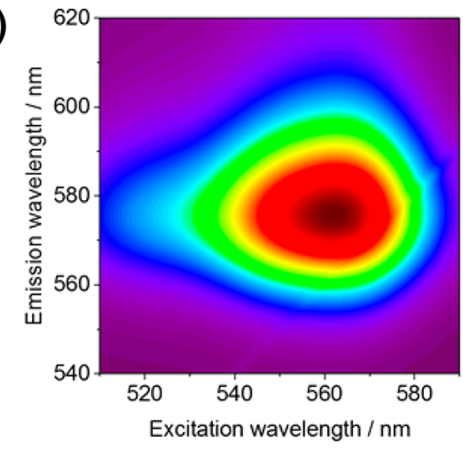

(c)

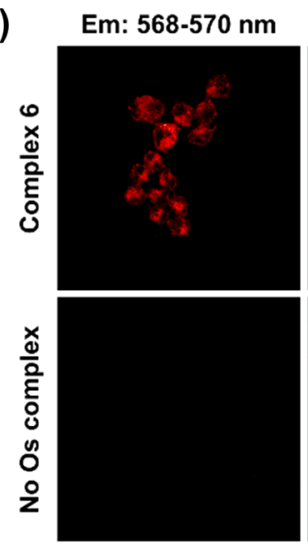

Complex 6
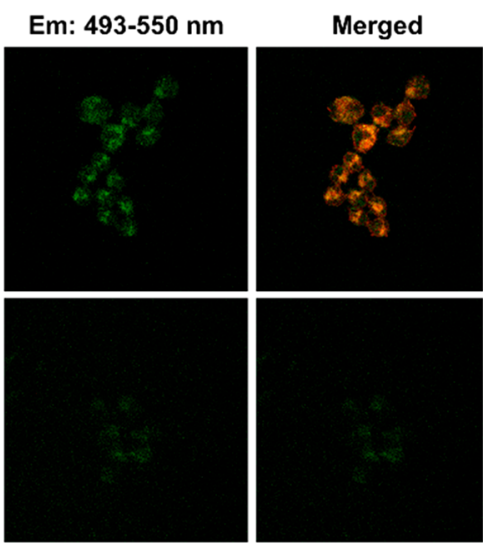

ROS

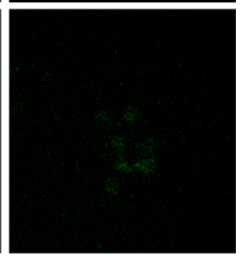
Os(II) sulfonamide complex 6 in acetonitrile, acquired using a Jasco FP-6500 Fluorimeter. (c) Confocal microscopy in A2780 cancer cells: containing with Os complex 6 (red) and ROS detection reagent (green) indicates the generation of ROS inside cells. Cells were stained using the green reagent of the ROS/Superoxide Detection Kit (Enzo life sciences) to detect ROS. Excitation, 458 and 488 nm; green emission for ROS, 493-550 nm.

selectivity between cells of ovarian origin, achieving up to $15 \times$ selectivity in the case of $10(0.15 \pm 0.01 \mu \mathrm{M}$ in $\mathrm{A} 2780$ compared to $2.32 \pm 0.01 \mu \mathrm{M}$ in $\mathrm{HOF}$ ), twice as selective as cisplatin $(8.5 \times)$. In contrast, the anticancer selectivity between lung cells was much less apparent, ca. $4 \times$ for $10(1.1 \pm 0.2 \mu \mathrm{M}$ in A549 compared to $4.5 \pm 0.3 \mu \mathrm{M}$ in MRC5), similar to cisplatin (Tables S1 and S2).

In Vitro Generation of Reactive Oxygen Species. Osmium azopyridine complexes have been shown to localize in the mitochondria of ovarian cancer cells using synchrotron Xray fluorescence. ${ }^{38}$ Furthermore, investigations into their mechanism of action indicate that the generation of reactive oxygen species (ROS) in cancer cells is highly relevant to their anticancer activity. ${ }^{14}$ In particular, for complex 10 RNA-seq data shows time-dependent activation of cellular pathways that link the generation of ROS to the observed mechanism of action and subsequent cell death. ${ }^{14}$ We investigated the generation of reactive oxygen species (ROS) by sulfonamide complex 1 compared to azopyridine complexes 9 and 10 . Although $\mathbf{1}$ is significantly less active than the azopyridine derivatives, all Os(II) complexes generated similar high levels of ROS and superoxide in A2780 human ovarian cancer cells upon exposure to equipotent drug concentrations (Figure 2 and Table S3).

We then investigated the generation of ROS in noncancerous HOF human ovarian fibroblasts (Table S4). Interestingly, the generation of ROS was significantly lower than that observed in A2780 cancer cells for both Os(II) azopyridine and sulfonamide complexes. The Q2 population (superoxide and ROS) decreased from $96 \%$ to $38 \%$, as we observed previously using MRC5 normal lung fibroblast cells exposed to 10. ${ }^{9,14}$ Normal cells are known to tolerate increased levels of oxidative stress better than cancer cells, and so selective generation of ROS in ovarian cancer cells can provide a novel targeted approach to chemotherapy, exploiting a key vulnerability of cancer cells. ${ }^{42}$

Electrochemical Investigations of Osmium Azopyridine Complexes. Due to the clear involvement of ROS in the mechanism of action of complex 10, the electrochemical behavior of $p$-cymene complex 10 (red) and structurally 
(A)

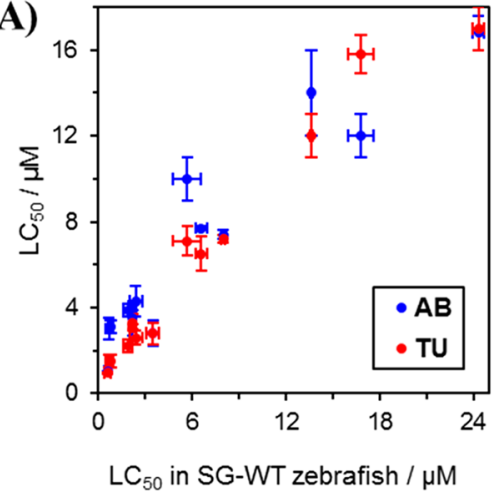

(B)

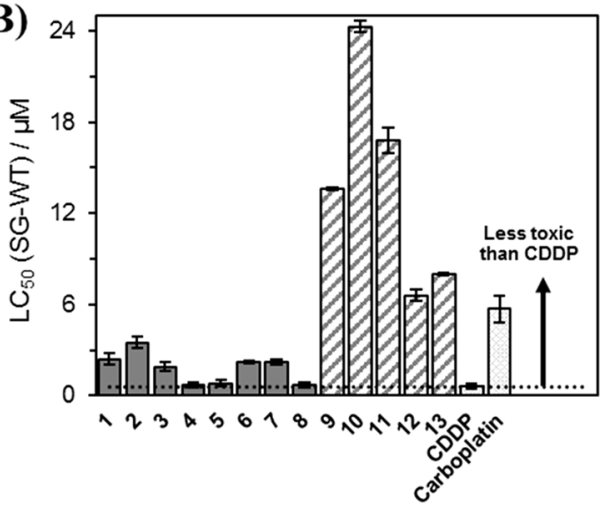

Figure 4. $\mathrm{LC}_{50}$ concentrations $(\mu \mathrm{M})$ for osmium complexes 1-13 and Pt anticancer drugs (cisplatin and carboplatin) determined in three zebrafish (Danio rerio) embryo wild-type strains: Singapore (SG), Tubingen (TU), and AB-wild type. (a) Trends in acute toxicity are maintained in all three wild-type strains of zebrafish embryo. (b) All osmium arene complexes are less toxic (higher $\mathrm{LC}_{50}$ ) than CDDP. See Table S5 for full numerical data.

similar biphenyl complex 12 (blue) were studied by cyclic voltammetry $(\mathrm{CV})$ using $\mathrm{Ag} / \mathrm{AgCl}(0.21 \mathrm{~V})$ as the reference electrode to determine ligand/metal based reduction potentials. The CVs of the two complexes $(-2.0 \mathrm{~V}$ to $+2.0 \mathrm{~V} ; 100$ $\mathrm{mV} / \mathrm{s} ; 10^{-3} \mathrm{M} ; \mathrm{CH}_{3} \mathrm{CN}$; see Figure S2) are in accordance with experimental CVs reported for structurally close arene osmium complexes. ${ }^{43}$ Both complexes 10 and $\mathbf{1 2}$, containing the strong $\pi$-acceptor ligand azpy, are reduced via two consecutive oneelectron steps, with simultaneous loss of the halide ligand $(\mathrm{Cl}$ and I, respectively): The first reduction step (ca. $-0.4 \mathrm{~V}$ ) is electrochemically reversible (Figure $3 b$ ), with no loss of halide, whereas the second step is strongly dissociative with respect to the halide ligand. Thus, the redox mechanism of both complexes is an EEC mechanism (E, one-electron transfer at the electrode; $\mathrm{C}$, chemical step, here, halide dissociation).

To investigate the redox behavior of both complexes in a biologically relevant range of potentials, $\mathrm{CV}$ spectra of $\mathbf{1 0}$ and 12 were monitored between $-0.7 \mathrm{~V}$ and $+0.7 \mathrm{~V}$ (Figure S3). Interestingly, for both complexes, the first one-electron step, without simultaneous loss of the halide ligand, is observed at a potential accessible for biological reductants. In this range of potentials, the absence of the second reduction wave allows the complexes to remain intact (no structural changes). This study suggests that ligand-centered redox processes of complexes 10 and $\mathbf{1 2}$ may be responsible for the ROS production in cancer cells. Further evidence of the link between ROS generation and the mechanism of action of complex $\mathbf{1 0}$ is its ability to produce $\mathrm{OH}$ radicals, which have been trapped using electron paramagnetic resonance (EPR) spectroscopy. ${ }^{44}$

Confocal Microscopy in Cancer Cells. To investigate cellular localization and further probe the mechanism of action, we synthesized a red-fluorescent Os(II) complex (6, Figure 3a) derived from complex 1. Such a red fluorescent complex facilitates coimaging of complex localization (red) and ROS generation (using the green-fluorescent ROS detection reagent in flow cytometry studies, Figure 2). Previous work has shown that $\mathrm{R}^{2}$ substituents have little effect on the antiproliferative properties of complexes $\mathbf{1 - 5},{ }^{10}$ and this was also the case for complex 6 (Figure 1). Optimal absorption and emission wavelengths for fluorescence studies were determined (ex/em $=560 / 580 \mathrm{~nm}$, Figure $3 \mathrm{~b}$ ). Perhaps surprisingly, fluorescence was not quenched by Os in the complex, unlike in several previous reports of labeling transition metal complexes. ${ }^{45}$
Next, A2780 cancer cells were treated with red-fluorescent complex 6 (Figure 3a) and then stained with the green ROSdetection reagent (Enzo Life Sciences, Figure 3c) previously used in our flow cytometry investigations (Figure 2). The two emission bands were readily resolved, and clear colocalization (yellow) was observed between green (ROS production) and red (complex 6) fluorescence. These data provide validation of previous cellular metal accumulation studies using ICP-MS and ROS generation studied by flow cytometry. Moreover, these images further implicate ROS production as a major contributor to the mechanism of action of such Os(II) arene complexes.

In Vivo Toxicity Studies. Since the compounds showed promise in vitro, in vivo toxicities were investigated using zebrafish embryos, following the well-established zebrafish embryo toxicity (FET) test (Figure 4). Strikingly, the osmium complexes $(1-13)$ were all less toxic, by up to $40 \times$ in the case of 10, toward zebrafish embryos compared to the anticancer drug cisplatin $\left(\mathrm{LC}_{50}=0.6 \pm 0.2 \mu \mathrm{M}\right.$ in SG-WT) in all three wild-type strains ( $\mathrm{AB}, \mathrm{SG}$, and $\mathrm{TU})$. Comparable activities were determined between wild-type embryos, suggesting that the origin of the strain selected for future study would not influence subsequent experimentation. A second-generation platinum anticancer drug, carboplatin, was found to be an order of magnitude less toxic than cisplatin $\left(\mathrm{LC}_{50}=5.7 \pm 0.9\right.$ $\mu \mathrm{M}$ in SG-WT) toward zebrafish. The lower toxicity of carboplatin (especially nephrotoxicity, ototoxicity, and neurotoxicity) is well documented in human clinical trials. Interestingly, Os(II) azopyridine complexes were significantly less toxic than sulfonamide complexes, displaying low toxicity $\left(\mathrm{LC}_{50}=24.3 \pm 0.4 \mu \mathrm{M}\right.$ in the case of complex 10 against SGWT embryos) in zebrafish (Figure 4 and Table S5).

In Vivo Generation of Reactive Oxygen Species: Does an in Vitro Mechanism of Action Translate to an in Vivo Animal Model? Since the in vitro mechanism of action of both Os(II) azopyridine and sulfonamide complexes appears to be strongly related to the generation of superoxide and ROS in cultured cancer cells, we investigated the translation of such mechanism of action to an in vivo model using zebrafish (Danio rerio) following an adapted literature procedure. ${ }^{46,47}$ Wholemount zebrafish embryos were exposed to equipotent solutions of Os(II) complexes 1 and $10\left(1.0 \times \mathrm{LC}_{50}\right)$ for $96 \mathrm{~h}$ and anaesthetized, then levels of reactive oxygen species were determined using a green fluorescent probe to detect ROS 

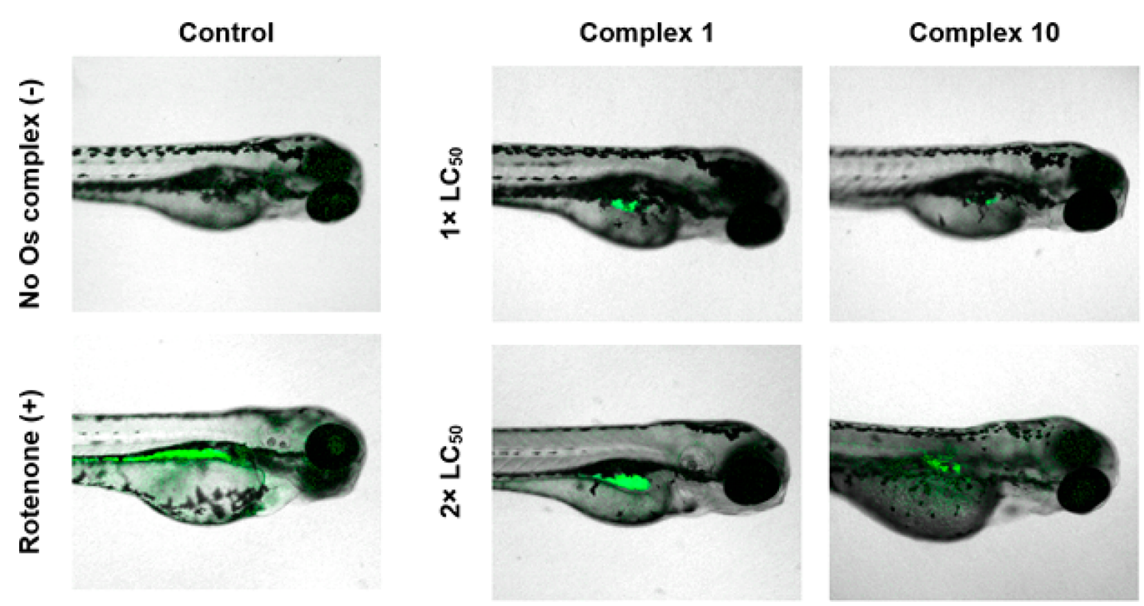

Figure 5. Reactive oxygen species (ROS) in anaesthetized whole-mount Singapore wild-type zebrafish (Danio rerio) treated with equipotent concentrations ( 1 or $2 \times L_{50}$ ) of Os-sulfonamide 1 or Os-azopyridine 10 for $96 \mathrm{~h}$. Fluorescence for ROS (green) is shown superimposed onto bright field images. Embryos were stained using the green reagent of the ROS/Superoxide Detection Kit (Enzo life sciences) to detect ROS. Excitation, 458 and $488 \mathrm{~nm}$; green emission for ROS, 493-550 nm. Rotenone was the positive control; $50 \mu \mathrm{M}, 2$ min exposure. ${ }^{47}$
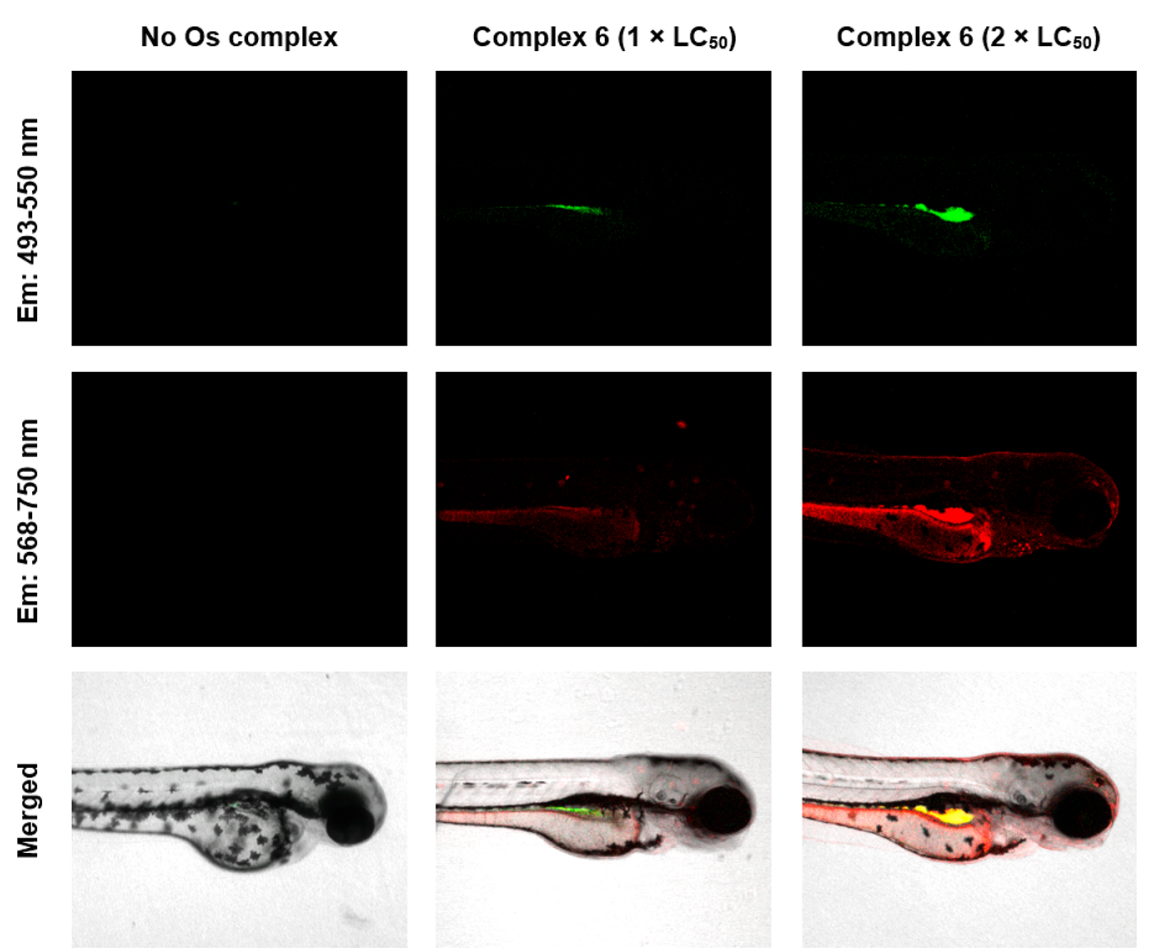

Figure 6. Two-color fluorescent imaging of whole mount SG-WT zebrafish (Danio rerio) treated with Os(II) sulfonamide 6 for 96 h. Fluorescence for ROS (green) and 6 (red) is shown superimposed onto bright field images. Overlapping regions (yellow) are shown. Confocal images were acquired using a Zeiss LSM880 confocal microscope. Embryos were stained using the green reagent of the ROS/Superoxide Detection Kit (Enzo life sciences) for ROS detection. Excitation, 458, 488, and $561 \mathrm{~nm}$; green emission for ROS, 493-550 nm; red emission for 6, 568-750 nm. See SI for full confocal data.

(including $\mathrm{H}_{2} \mathrm{O}_{2}$, peroxynitrite, and hydroxyl radicals) and analyzed using confocal microscopy.

Good dye localization was observed in the positive control (4 dpf zebrafish exposed to $50 \mu \mathrm{M}$ rotenone for $5 \mathrm{~min}$ ). Complexes 1 and 10 generated elevated levels of ROS in vivo in a concentration-dependent manner. ROS generated by treatment with Os-sulfonamide $\mathbf{1}$ appeared to locate largely in the swim bladder, whereas Os-azopyridine 10-generated ROS were more broadly distributed across the organism (Figure 5). Though the drug concentration was an order of magnitude less for $\mathbf{1}(2.4 \mu \mathrm{M}$ compared to $24.3 \mu \mathrm{M})$, the levels of ROS appear qualitatively higher than in those treated with 10, which may be related to the radical induction efficiency.

Interestingly, complex 1 can catalyze transfer hydrogenation reactions in cells using formate as a hydride source, perturbing the cellular redox balance. ${ }^{10}$ Micromolar levels of formate are present in human serum, ${ }^{48}$ and while formate biochemistry in zebrafish is not fully understood, humans and zebrafish share similar one-carbon pathways. ${ }^{49}$ The catalytic properties of $\mathbf{1}$ may explain why ROS were present in qualitatively greater amounts, despite the administered concentration of $\mathbf{1 0}$ being an order of magnitude greater. 
Since ROS were highly localized in zebrafish treated with $\mathbf{1}$, we explored methods for determining drug localization in vivo. Laser ablation coupled to inductively coupled plasma mass spectrometry (LA-ICP-MS), ${ }^{50}$ nanoscale secondary ion mass spectrometry (nanoSIMS) imaging, ${ }^{51}$ and electron microscopy $^{52}$ have been explored for the detection of metal ions and nanoparticles in zebrafish. Confocal microscopy and fluorescent complex 6 provide an alternative strategy, which utilizes the transparent properties of zebrafish embryos. Zebrafish treated with red-fluorescent osmium complex 6 showed red fluorescence, indicative of in vivo complex localization. Remarkably, the in vivo distribution of ROS was similar to the internal localization of $\mathbf{6}$, as shown by the yellow areas (Figure 6), implicating the complex in the production of ROS. When taken with the statistically similar in vitro and in vivo activities of $\mathbf{1}$ and 6, it appears that the fluorescent marker had little influence on the biological interactions of the complex.

These studies confirm the high anticancer potency of osmium azopyridine complexes. ${ }^{2,93}$ Elevated levels of ROS were detected in A2780 cancer cells treated with nanomolar concentrations of $\mathbf{1 0}$ (Figure 2, Table S3); yet at micromolar concentrations, significantly lower levels were detected in noncancerous fibroblasts and in vivo in zebrafish (Table S4), despite the more than an order of magnitude higher dosage.

\section{DISCUSSION AND CONCLUSIONS}

Whereas half-sandwich osmium(II) arene azopyridine complexes can exhibit highly potent anticancer activity, ${ }^{21,53}$ sulfonamide complexes showed only moderate activity, highlighting the important role played by the $N, N$-bidentate ligand. In the cell lines investigated in this study, the osmium complexes exhibited highest potency against A2780 ovarian cancer cells, achieving nanomolar potency, compared to lower potency of previously reported $\mathrm{Ru}$ (II) analogues ( $\mathrm{IC}_{50} 2-6$ $\mu \mathrm{M}$, depending on azopyridine ligand and $\eta^{6}$-arene). ${ }^{54}$ In the clinic, ovarian cancers are commonly treated with platinum anticancer complexes; ${ }^{39}$ however, both intrinsic and acquired resistance mechanisms reduce the efficacy of platinum-based therapies, highlighting the importance for the development of anticancer agents that operate by alternative mechanism(s) of action. ${ }^{5}$ Remarkably, azopyridine complexes 9-13 were found to circumvent cisplatin resistance, determined by comparing antiproliferative activities in A2780cis cisplatin-resistant cells compared to parental A2780 cells, and HCT116Ox oxaliplatinresistant cells and parental HCT116 cells. In contrast, sulfonamide complexes appeared to share common resistance mechanisms with cisplatin, reflected by their lower potencies toward platinum-resistant cells compared to platinum-sensitive cells. The mechanisms of acquired resistance, particularly between A2780 and A2780 Cis resistant cells are well established. These include reduced cellular uptake and increased cellular efflux (both of which result in reduced cellular accumulation), as well as increased DNA repair. Hence, it is reasonable to hypothesize that azopyridine complexes 9-13 may have differences in uptake and efflux pathways compared to cisplatin and a mechanism of action, which is not DNA based, centered on ROS induction. Similarly, the $P 21 / P 53$ status was not found to affect antiproliferative activities to the same extent as for cisplatin (over an order of magnitude activity decrease in the P53 knockout cell line). Maintaining anticancer activity in cell lines that have mutations in p53 is important, as it is well established that such a mutation is present in approximately 50\% of all colorectal cancers. ${ }^{41}$ Clinical cases are prime examples of inherent platinum resistance. Taken together, these data suggest that the in vitro mechanism of action for Os-arene complexes, particularly for complexes bearing an azopyridine ligand, differs greatly from current platinum-based therapies ${ }^{55}$ and that they could be further developed to target both acquired and inherent platinum resistance.

The selective generation of reactive oxygen species in cancer cells has been suggested as a novel targeted approach to chemotherapy, which exploits a key vulnerability of cancer cells. ${ }^{42}$ When exposed to either complex 1 [Os $(p$-cymene)$(\mathrm{TsDPEN})]$ or $10\left[\mathrm{Os}(p \text {-cymene })\left(\mathrm{AzPy}-\mathrm{NMe}_{2}\right) \mathrm{I}\right]^{+}$in an equipotent manner, comparable levels of ROS/superoxide were detected in A2780 cancer cells (Table S1: $96 \pm 1$ and $95.4 \pm 0.2 \%$, respectively), indicative of a common mechanism of action for piano-stool osmium complexes involving redox modulation. However, in noncancerous ovarian fibroblasts, sulfonamide complex 1 generated significantly more ROS (FL1 channel) than azopyridine complex 10 (Table S2), suggesting that the nature of the $N, N$-bidentate ligand is crucial to the biological activity of the complexes and highlighting the efficacy of azopyridine complexes, which may exhibit fewer side effects if excessive ROS production is selective for cancer cells.

To confirm internalization of the osmium complex in vivo, fluorescent rhodamine complex 6 was synthesized and investigated in vivo using confocal microscopy. The localization of the complex in zebrafish embryos correlated well with oxidative stress, further implicating the involvement of the osmium complex in the production of ROS.

Elevated levels of ROS were detected in A2780 cancer cells treated with nanomolar concentrations of $\mathbf{1 0}$ (Figure 2, Table S3); yet at micromolar concentrations, significantly lower levels were detected in vitro using noncancerous fibroblasts and in vivo using zebrafish (Table S2), despite the more than an order of magnitude higher dosage. In these experiments, azopyridine complex $\mathbf{1 0}$ has shown clinical promise for the selective generation of oxidative stress in cancer cells over noncancerous cells and, to a lesser extent, in a whole organism model. Beyond using zebrafish as a toxicity model, future work might investigate the efficacy of complex $\mathbf{1 0}$ in tumor-bearing zebrafish since $\mathbf{1 0}$ has previously been shown to delay the growth of xenografts (HCT116 human colorectal cancer cells) in mice. ${ }^{8}$ In agreement with our findings using zebrafish, few toxic side effects were observed in the xenograft-bearing mice, reflected in a lack of clinical toxicity signs mice. ${ }^{8}$ Overall, it is apparent that the nature of the chelated ligand is highly influential over the biological properties of the complexes and crucially over the selective generation of reactive oxygen species in cancer cells compared to normal cells and living organisms. Determination of metallodrug speciation in a biological environment is crucial for further understanding of both the mechanism of action and the design of future metalbased anticancer agents.

\section{EXPERIMENTAL SECTION}

Materials. Osmium trichloride trihydrate was obtained from Heraeus South Africa Ltd. and Heraeus GmbH. (1R,2R)-Diphenylethylenediamine was purchased from Arran Chemical Company (Ireland). Ascorbic acid, carboplatin, cisplatin (CDDP), dimethyl sulfoxide (DMSO), sodium chloride, sulforhodamine $\mathrm{B}$ acid chloride, tricaine $\left(4 \mathrm{mg} \cdot \mathrm{mL}^{-1}\right.$ tricaine powder in doubly deionized water, adjusted to $\mathrm{pH} 7$ using Tris base), and thiourea were purchased from 
Sigma-Aldrich (UK). Magnesium sulfate, potassium hydroxide, and all nondried solvents were purchased from Fischer Scientific. Hanks Balanced Salt Solution (HBSS) was purchased from Scientific Laboratory Supplies. ROS/superoxide detection kit was purchased from Enzo Life Sciences (UK). Hoechst-33258 and Alexa Fluor 633 Phallodin were purchased from ThermoFischer. Concentrated nitric acid $(72 \% \mathrm{v} / \mathrm{v})$ was freshly distilled before use. All reagents were used as received unless specified. Singapore wild-type (SG-WT) zebrafish were maintained in reverse-osmosis (RO) water supplemented with Aquavitro salt ( $\mathrm{pH}$ 7.5). GEMMA micro powder food for zebrafish was purchased from Skretting. Live food (Artemia salina) was purchased from ZM Fish Food.

Instrumentation. Mass Spectrometry (HR-MS). Low resolution ESI-MS spectra for ligand L6 and complex 6 dissolved in acetonitrile were obtained using an Agilent 6130B ESI mass spectrometer. High resolution mass spectra were kindly acquired by Dr. L Song and Mr. Phillip Aston using a Bruker UHR-Q-TOF MaXis, with a positive ion scan range of $\mathrm{m} / z$ 50-3000. Analysis was carried out through direct infusion $(2 \mu \mathrm{L} / \mathrm{min})$ with a syringe pump, with sodium formate (10 $\mathrm{mM})$ calibration. Source conditions, ESI (+); end plate offset, -500 $\mathrm{V}$; capillary, $-3000 \mathrm{~V}$; nebulizer gas $\left(\mathrm{N}_{2}\right), 0.4$ bar; dry gas $\left(\mathrm{N}_{2}\right), 4 \mathrm{~L} /$ min; dry temperature, $453 \mathrm{~K}$; funnel RF, $200 \mathrm{Vpp}$; multiple RF, 200 Vpp; quadruple low mass, $55 \mathrm{~m} / z$; collision energy, $5.0 \mathrm{eV}$; collision $\mathrm{RF}, 600 \mathrm{Vpp}$; ion cooler RF, 50-250 Vpp ramping; transfer time, 121 $\mu \mathrm{s}$; prepulse storage time, $1 \mu \mathrm{s}$.

Elemental Analysis (CHN). Elemental analysis for ligand L6 and complex 6 was carried out by Warwick Analytical Services UK on an Exeter elemental analyzer CE440.

Nuclear Magnetic Resonance Spectroscopy (NMR). Spectra for ligand $\mathbf{L} 6$ and complex $\mathbf{6}$ were acquired for $\mathrm{CD}_{3} \mathrm{CN}$ solutions in $5 \mathrm{~mm}$ NMR tubes (Sigma-Aldrich, UK). ${ }^{1} \mathrm{H}$, COSY, and ${ }^{13} \mathrm{C}$ NMR spectra were recorded using a Bruker HD-500 NMR spectrometer using standard pulse sequences. Chemical shifts were referenced to residual solvent and processed using Topspin 3.2 (Bruker, UK).

Inductively Coupled Plasma Optical Emission Spectroscopy (ICP-OES). Data were obtained using a PerkinElmer Optima 5300 DV Optical Emission Spectrophotometer, using a calibration range from 50 to $700 \mathrm{ppb}$, freshly prepared in $3.6 \% \mathrm{v} / \mathrm{v}$ nitric acid containing thiourea $(10 \mathrm{mM})$ and ascorbic acid $(100 \mathrm{mg} / \mathrm{L})$ to stabilize osmium in nitric acid solution. ${ }^{56}$ Samples were diluted accordingly, and the salinity of the calibration adjusted to match the matrix of the samples by standard addition of sodium chloride solution. Os $(\lambda=225.585$, $228.226 \mathrm{~nm}), \operatorname{Ir}(\lambda=208.882,237.277 \mathrm{~nm})$, and $\mathrm{Pt}(\lambda=265.945$, $204.937 \mathrm{~nm}$ ).

Inductively Coupled Plasma Mass Spectrometry (ICP-MS). ICPMS data were obtained using either an Agilent 7500 series or Agilent 7900 series ICP-MS with an internal standard of ${ }^{166} \mathrm{Er}(50 \mathrm{ppb})$ in both no-gas and He-gas mode. Calibration standards for Os (0.1$1000 \mathrm{ppb}$ ) were freshly prepared in $3.6 \% \mathrm{v} / \mathrm{v}$ nitric acid containing thiourea $(10 \mathrm{mM})$ and ascorbic acid $(100 \mathrm{mg} / \mathrm{L})$ to stabilize osmium in nitric acid solution. ${ }^{56}$ Data were acquired and processed using Agilent ChemStation for Windows (7500 series ICP-MS) or Agilent Mass Hunter 4.3 for Windows (7900 series ICP-MS).

Three-Dimensional Fluorescence Spectroscopy. Spectra for complex 6 (dissolved in acetonitrile, $\sim 0.01 \mathrm{mM}$ ) were acquired using a Jasco FP-6500 Fluorimeter, with path length of $1 \mathrm{~cm}$.

Confocal Microscopy (Cancer Cells). A2780 cancer cells treated with Os(II) complex $6\left(0.5 \times\right.$ and $1.0 \times \mathrm{IC}_{50} ; 24 \mathrm{~h}$ exposure $)$ were washed with PBS and stained using green ROS detection reagent (2 $\mu \mathrm{M}$, Enzo Life Sciences). Cells were analyzed using a Zeiss LSM880 confocal microscope (Argon laser; excitation, 458, 488, and $561 \mathrm{~nm}$; green emission for ROS, $493-550 \mathrm{~nm}$; red emission for complex 6, $568-750 \mathrm{~nm}$ ). Data were processed using Zen 2.3 for Windows.

Confocal Microscopy (Zebrafish). Whole-mount zebrafish were analyzed using a Zeiss LSM880 confocal microscope (Argon laser; excitation, 458, 488, and $561 \mathrm{~nm}$; green emission for ROS, 493-550 $\mathrm{nm}$; red emission for complex 6, 568-750 nm). Data were processed using Zen 2.3 for Windows.

Chemical Synthesis. The synthesis and full characterization of complexes 1-5 and 7-13 have been previously reported. ${ }^{10,21}$ The purity of all compounds determined by $\mathrm{C}, \mathrm{H}$, and $\mathrm{N}$ combustion elemental analysis was $\geq 95 \%$.

2-(3-Diethylamino-6-diethylazaniumylidene-xanthen-9-yl)-5-( $N$ (2-amino-1,2-diphenyl-ethyl)sulfonoyl)-benzenesulfonate (Ligand L6). (1R,2R)-1,2-Diphenylethylenediamine $(112 \mathrm{mg}, 0.58 \mathrm{mmol}, 1$ mol equiv) and triethylamine $(117 \mathrm{mg}, 160 \mu \mathrm{L}, 1.16 \mathrm{mmol}, 2 \mathrm{~mol}$ equiv) were dissolved in dichloromethane $(2 \mathrm{~mL})$ at $273 \mathrm{~K}$. Sulforhodamine B acid chloride $(400 \mathrm{mg}, 0.69 \mathrm{mmol}, 1.2 \mathrm{~mol}$ equiv) in dichloromethane $(2 \mathrm{~mL})$ was added dropwise over $3 \mathrm{~h}$. The solution was washed with water $(10 \times 25 \mathrm{~mL})$ and aqueous fractions extracted with dichloromethane $(3 \times 10 \mathrm{~mL})$. Organic fractions were dried over magnesium sulfate, and the solvent was removed to yield a dark purple amorphous solid (78.6 mg, $0.104 \mathrm{mmol}, 18 \%) .{ }^{1} \mathrm{H}$ NMR $\left(500 \mathrm{MHz}, \mathrm{CD}_{3} \mathrm{CN}, 25^{\circ} \mathrm{C}\right.$, TMS $): \delta=8.43(\mathrm{~s}, 1 \mathrm{H}, \mathrm{ArH}), 7.49(\mathrm{~m}$, $1 \mathrm{H}, \mathrm{ArH}), 7.38(\mathrm{~m}, 1 \mathrm{H}, \mathrm{ArH}), 6.88-7.35(\mathrm{~m}, 14 \mathrm{H}, \mathrm{ArH}), 6.81(\mathrm{~m}$, $2 \mathrm{H}, \mathrm{ArH}), 4.55\left(\mathrm{~d},{ }^{3} \mathrm{~J}(\mathrm{H}, \mathrm{H})=7.4 \mathrm{~Hz}, 1 \mathrm{H}, \mathrm{CHNH}\right), 4.15\left(\mathrm{~d},{ }^{3} J(\mathrm{H}, \mathrm{H})\right.$ $=7.4 \mathrm{~Hz}, 1 \mathrm{H}, \mathrm{CHNH}), 3.58-3.73\left(\mathrm{~m}, 8 \mathrm{H}, \mathrm{CH}_{2}\right), 1.24-1.33(\mathrm{~m}$, $\left.12 \mathrm{H}, \mathrm{CH}_{3}\right) .{ }^{13} \mathrm{C}$ NMR $\left(125 \mathrm{MHz}, \mathrm{CD}_{3} \mathrm{CN}, 25{ }^{\circ} \mathrm{C}\right.$, TMS $) \delta 158.8$, 158.2 , 156.0, 148.4, 143.0, 142.6, 139.6, 133.5, 133.4, 130.0, 128.6, $128.5,128.3,128.2,127.8,127.6,127.5,127.4,127.4,127.3,127.0$, $126.8,113.6,95.9,65.1,61.2,60.2,59.8,50.0,12.2$. UV/vis: $\lambda_{\max } 557$, 399, 353, 307, 281, $258 \mathrm{~nm}$. HRMS $(\mathrm{m} / z):[\mathrm{M}+\mathrm{H}]^{+}$calcd. for $\mathrm{C}_{41} \mathrm{H}_{45} \mathrm{~N}_{4} \mathrm{O}_{6} \mathrm{~S}_{2}, 753.2775$; found, 753.2769. Analysis (calcd., found for $\left.\mathrm{C}_{41} \mathrm{H}_{44} \mathrm{~N}_{4} \mathrm{O}_{6} \mathrm{~S}_{2}\right)$ : C $(65.40,65.05), \mathrm{H}(5.89,6.04), \mathrm{N}(7.44,7.62)$.

[Os $\left(\eta^{6}-p\right.$-Cymene)(SrbDPEN)] (Complex 6). [Os $\left(\eta^{6}\right.$-Biphenyl)$\left.\mathrm{Cl}_{2}\right]_{2}$ (15.7 $\mathrm{mg}, 0.02 \mathrm{mmol}, 1 \mathrm{~mol}$ equiv) and $(1 R, 2 R)$-SrbDPEN ( $30 \mathrm{mg}, 0.04 \mathrm{mmol}, 2 \mathrm{~mol}$ equiv) were stirred in chloroform $(5 \mathrm{~mL})$ with freshly ground potassium hydroxide $(22.4 \mathrm{mg}, 0.40 \mathrm{mmol}, 20$ mol equiv) for $5 \mathrm{~min}$, after which time water was added $(10 \mathrm{~mL})$ with vigorous stirring for a further $10 \mathrm{~min}$. The organic layer was washed with water $(3 \times 10 \mathrm{~mL})$ and concentrated under reduced pressure to yield a purple oil, which was dissolved in the minimum amount of dichloromethane, and a dark purple solid precipitated using $n$-pentane (13 mg, $0.012 \mathrm{mmol}, 61 \%) .{ }^{1} \mathrm{H}$ NMR $\left(500 \mathrm{MHz}, \mathrm{CD}_{3} \mathrm{CN}, 25{ }^{\circ} \mathrm{C}\right.$, TMS $): \delta=6.70-8.64(\mathrm{~m}, 19 \mathrm{H}, \operatorname{ArH}), 6.14\left(\mathrm{~d},{ }^{3} J(\mathrm{H}, \mathrm{H})=5.5 \mathrm{~Hz}, 1 \mathrm{H}\right.$, Os-ArH), $6.03\left(\mathrm{~d},{ }^{3} \mathrm{~J}(\mathrm{H}, \mathrm{H})=5.5 \mathrm{~Hz}, 1 \mathrm{H}, \mathrm{Os}-\mathrm{ArH}\right), 5.90(\mathrm{~m}, 2 \mathrm{H}, \mathrm{Os}-$ $\operatorname{ArH}), 4.40(\mathrm{~s}, 1 \mathrm{H}, \mathrm{CHNTs}), 3.96\left(\mathrm{~d},{ }^{3} J(\mathrm{H}, \mathrm{H})=4.4 \mathrm{~Hz}, 1 \mathrm{H}\right.$, $\mathrm{CHNH}), 3.55-3.74\left(\mathrm{~m}, 8 \mathrm{H}, \mathrm{CH}_{2}\right), 2.90\left(\mathrm{sept}^{3} \mathrm{~J}(\mathrm{H}, \mathrm{H})=7.0 \mathrm{~Hz}, 1 \mathrm{H}\right.$, $\left.\mathrm{CH}\left(\mathrm{CH}_{3}\right)_{2}\right), 2.31\left(\mathrm{~s}, 3 \mathrm{H}, \mathrm{CH}_{3}\right), 1.25-1.35\left(\mathrm{~m}, 12 \mathrm{H}, \mathrm{CH}_{3}\right), 1.23(\mathrm{~d}$ $\left.{ }^{3} \mathrm{~J}(\mathrm{H}, \mathrm{H})=7.0 \mathrm{~Hz}, 6 \mathrm{H}, \mathrm{CH}\left(\mathrm{CH}_{3}\right)_{2}\right) \cdot{ }^{13} \mathrm{C} \mathrm{NMR}\left(125 \mathrm{MHz}, \mathrm{CD}_{3} \mathrm{CN}\right.$ $25^{\circ} \mathrm{C}$, TMS) $\delta 159.7,158.2,156.0,133.9,133.7,133.5,129.5,129.3$, $128.9,128.6,128.5,128.4,128.3,128.2,128.0,127.9,127.7,127.5$ $127.2,126.9,126.7,126.6,126.1,113.6,113.5,113.4,95.8,91.6,83.6$, 81.0, 77.0, 74.1, 73.1, 69.7, 71.2, 68.2, 63.8, 63.2, 58.7, 58.5, 46.0, $45.9,33.9,33.0,31.2,23.8,23.3,23.2,20.6,18.6,12.3$. UV/vis: $\lambda_{\max }$ 555, 398, 352, 281, $258 \mathrm{~nm}$. HRMS $(\mathrm{m} / \mathrm{z}):[\mathrm{M}+\mathrm{H}]^{+}$calcd. for $\mathrm{C}_{51} \mathrm{H}_{57} \mathrm{~N}_{4} \mathrm{O}_{6} \mathrm{OsS}_{2}, 1077.3329$; found, 1077.3337. Analysis (calcd., found for $\left.\mathrm{C}_{51} \mathrm{H}_{56} \mathrm{~N}_{4} \mathrm{O}_{6} \mathrm{OsS}_{2}\right)$ : $\mathrm{C}(56.96,56.82), \mathrm{H}(5.25,5.06), \mathrm{N}$ $(5.21,4.84)$.

\section{ASSOCIATED CONTENT}

\section{Supporting Information}

The Supporting Information is available free of charge on the ACS Publications website at DOI: 10.1021/acs.jmedchem.8b00958.

Experimental details regarding the in vitro and in vivo biological studies; numerical values for antiproliferative activity of complexes 1-13 and cisplatin in parental and resistant cancer cell lines; cell population percentages for the flow cytometry detection of ROS in A2780 cancer cell line and HOF human ovarian fibroblasts; $\mathrm{LC}_{50}$ concentrations in three zebrafish embryo wild-type strains; ROS detection in whole mount SG-WT zebrafish by confocal microscopy; cyclic voltammetry studies for complexes 10 and 12; inhibition of PgPmediated Os efflux by verapamil (PDF)

Molecular formulas strings (XLSX) 


\section{AUTHOR INFORMATION}

Corresponding Author

*E-mail: I.RomeroCanelon@bham.ac.uk.

ORCID $\odot$

James P. C. Coverdale: 0000-0002-7779-6620

Nicolas P. E. Barry: 0000-0002-0388-6295

Peter J. Sadler: 0000-0001-9160-1941

Isolda Romero-Canelón: 0000-0003-3847-4626

\section{Author Contributions}

J.P.C.C. carried out all chemical synthesis and physicochemical analysis. N.S. and N.P.E.B carried out electrochemistry studies. J.P.C.C. H.E.B., J.I.S., I.B., and I.R.C. carried out biological studies. J.P.C.C. and I.R.C. are joint-first authors of the manuscript. The manuscript was written through contributions of all authors. All authors have given approval to the final version of the manuscript.

\section{Funding}

Wellcome Trust (grant no. 107691/Z/15/Z), ERC (grant nos. 247450, 324594), Science City (AWM and ERDF), WCPRS and Bruker Daltonics (Studentship for JPCC), Mike and Enfys Bagguley, and EPSRC (Studentship for HEB, and grant no. EP/F034210/1).

\section{Notes}

The authors declare no competing financial interest.

\section{ACKNOWLEDGMENTS}

We thank EU COST Action CM1105 for stimulating discussions, Dr. R. Needham for the synthesis and characterization of azopyridine complexes, S. Heer for assistance with cell culture studies, Dr. V. Venkatesh for assistance with 3D fluorescence spectroscopy, I. Hands-Portman and E. Bolitho for support with confocal microscopy, Miss S. Dixon and Dr. K. Sampath for guidance with zebrafish, Dr. L. Song and P. Aston for mass spectrometry, and Dr. I. Prokes for NMR spectroscopy. We also thank Heraeus $\mathrm{GmbH}$ for gifted osmium trichloride.

\section{ABBREVIATIONS USED}

AzPy, 2-phenylazopyridine; CDDP, cisplatin; $\mathrm{IC}_{50}$, halfmaximal inhibitory concentration; $\mathrm{LC}_{50}$, half-maximal lethal concentration; PgP, P-glycoprotein; ROS, reactive oxygen species; SG-WT, Singapore wild-type (zebrafish); TsDPEN, $N$-tosyl-1,2-diphenylethylenediamine; TU-WT, Tubingen wild-type (zebrafish)

\section{REFERENCES}

(1) Siegel, R. L.; Miller, K. D.; Jemal, A. Cancer statistics, 2016. CaCancer J. Clin. 2016, 66 (1), 7-30.

(2) Jemal, A.; Bray, F.; Center, M.; Ferlay, J.; Ward, E.; Forman, D. Global Cancer Statistics. Ca-Cancer J. Clin. 2011, 61 (2), 69-90.

(3) Dasari, S.; Bernard Tchounwou, P. Cisplatin in cancer therapy: Molecular mechanisms of action. Eur. J. Pharmacol. 2014, 740, 364378.

(4) Chen, H. H. W.; Kuo, M. T. Role of glutathione in the regulation of cisplatin resistance in cancer chemotherapy. Met.-Based Drugs 2010, 2010, 3070-3074.

(5) Johnson, S. W.; Shen, D. W.; Pastan, I.; Gottesman, M. M.; Hamilton, T. C. Cross-resistance, cisplatin accumulation, and platinum-DNA adduct formation and removal in cisplatin-sensitive and -resistant human hepatoma cell lines. Exp. Cell Res. 1996, 226 (1), 133-139.
(6) Köberle, B.; Tomicic, M. T.; Usanova, S.; Kaina, B. Cisplatin resistance: Preclinical findings and clinical implications. Biochim. Biophys. Acta, Rev. Cancer 2010, 1806 (2), 172-182.

(7) Fu, Y.; Habtemariam, A.; Pizarro, A. M.; van Rijt, S. H.; Healey, D. J.; Cooper, P. A.; Shnyder, S. D.; Clarkson, G. J.; Sadler, P. J. Organometallic osmium arene complexes with potent cancer cell cytotoxicity. J. Med. Chem. 2010, 53 (22), 8192-8196.

(8) Shnyder, S. D.; Fu, Y.; Habtemariam, A.; van Rijt, S. H.; Cooper, P. A.; Loadman, P. M.; Sadler, P. J. Anti-colorectal cancer activity of an organometallic osmium arene azopyridine complex. MedChemComm 2011, 2 (7), 666-668.

(9) Romero-Canelón, I.; Mos, M.; Sadler, P. J. Enhancement of selectivity of an organometallic anticancer agent by redox modulation. J. Med. Chem. 2015, 58 (19), 7874-7880.

(10) Coverdale, J. P. C.; Romero-Canelón, I.; Sanchez-Cano, C.; Clarkson, G. J.; Habtemariam, A.; Wills, M.; Sadler, P. J. Asymmetric transfer hydrogenation by synthetic catalysts in cancer cells. Nat. Chem. 2018, 10, 347-354.

(11) Hanif, M.; Babak, M. V.; Hartinger, C. G. Development of anticancer agents: wizardry with osmium. Drug Discovery Today 2014, 19 (10), 1640-1648.

(12) Berger, G.; Grauwet, K.; Zhang, H.; Hussey, A.; Nowicki, M.; Wang, D.; Antonio Chiocca, E.; Lawler, S.; Lippard, S. J. Anticancer activity of osmium(VI) nitrido complexes in patient-derived glioblastoma initiating cells and in vivo mouse models. Cancer Lett. 2017, 416, 138-148.

(13) Suntharalingam, K.; Johnstone, T. C.; Bruno, P. M.; Lin, W.; Hemann, M. T.; Lippard, S. J. Bidentate Ligands on Osmium(VI) Nitrido Complexes Control Intracellular Targeting and Cell Death Pathways. J. Am. Chem. Soc. 2013, 135 (38), 14060-14063.

(14) Hearn, J. M.; Romero-Canelón, I.; Munro, A. F.; Fu, Y.; Pizarro, A. M.; Garnett, M. J.; McDermott, U.; Carragher, N. O.; Sadler, P. J. Potent organo-osmium compound shifts metabolism in epithelial ovarian cancer cells. Proc. Natl. Acad. Sci. U. S. A. 2015, 112 (29), E3800-E3805.

(15) Liou, G.-Y.; Storz, P. Reactive oxygen species in cancer. Free Radical Res. 2010, 44 (5), 479-496.

(16) Queiroz, E. A. I. F.; Puukila, S.; Eichler, R.; Sampaio, S. C.; Forsyth, H. L.; Lees, S. J.; Barbosa, A. M.; Dekker, R. F. H.; Fortes, Z. B.; Khaper, N. Metformin induces apoptosis and cell cycle arrest mediated by oxidative stress, AMPK and FOXO3a in MCF-7 breast cancer cells. PLoS One 2014, 9 (5), e98207.

(17) Wang, X.; Liu, J.; Jiang, L.; Wei, X.; Niu, C.; Wang, R.; Zhang, J.; Meng, D.; Yao, K. Bach1 induces endothelial cell apoptosis and cell-cycle arrest through ROS generation. Oxid. Med. Cell. Longevity 2016, 2016, 13.

(18) Boonstra, J.; Post, J. A. Molecular events associated with reactive oxygen species and cell cycle progression in mammalian cells. Gene 2004, 337, 1-13.

(19) Kim, S.-H.; Kim, K.-Y.; Yu, S.-N.; Park, S.-G.; Yu, H.-S.; Seo, Y.K.; Ahn, S.-C. Monensin induces PC-3 prostate cancer cell apoptosis via ROS production and $\mathrm{Ca} 2+$ homeostasis disruption. Anticancer Res. 2016, 36 (11), 5835-5843.

(20) Schumacker, P. T. Reactive oxygen species in cancer: a dance with the devil. Cancer Cell 2015, 27 (2), 156-157.

(21) Fu, Y.; Romero, M. J.; Habtemariam, A.; Snowden, M. E.; Song, L.; Clarkson, G. J.; Qamar, B.; Pizarro, A. M.; Unwin, P. R.; Sadler, P. $\mathrm{J}$. The contrasting chemical reactivity of potent isoelectronic iminopyridine and azopyridine osmium(II) arene anticancer complexes. Chem. Sci. 2012, 3 (8), 2485-2494.

(22) Bowman, T. V.; Zon, L. I. Swimming into the future of drug discovery: in vivo chemical screens in zebrafish. ACS Chem. Biol. 2010, 5 (2), 159-161.

(23) Tan, J. L.; Zon, L. I., Chapter 21 - Chemical screening in zebrafish for novel biological and therapeutic discovery. In Methods in Cell Biology; William, H., Detrich, M. W., Leonard, I. Z., Eds.; Academic Press: 2011; Vol. 105, pp 491-516. 
(24) Eimon, P. M.; Rubinstein, A. L. The use of in vivo zebrafish assays in drug toxicity screening. Expert Opin. Drug Metab. Toxicol. 2009, 5 (4), 393-401.

(25) Rennekamp, A. J.; Peterson, R. T. 15 years of zebrafish chemical screening. Curr. Opin. Chem. Biol. 2015, 24, 58-70.

(26) Barbazuk, W. B.; Korf, I.; Kadavi, C.; Heyen, J.; Tate, S.; Wun, E.; Bedell, J. A.; McPherson, J. D.; Johnson, S. L. The syntenic relationship of the zebrafish and human genomes. Genome Res. 2000, 10 (9), 1351-1358.

(27) Sipes, N. S.; Padilla, S.; Knudsen, T. B. Zebrafish-As an integrative model for twenty-first century toxicity testing. Birth Defects Res., Part C 2011, 93 (3), 256-267.

(28) Murphey, R. D.; Stern, H. M.; Straub, C. T.; Zon, L. I. A chemical genetic screen for cell cycle inhibitors in zebrafish embryos. Chem. Biol. Drug Des. 2006, 68 (4), 213-219.

(29) Li, Y.; Huang, W.; Huang, S.; Du, J.; Huang, C. Screening of anti-cancer agent using zebrafish: comparison with the MTT assay. Biochem. Biophys. Res. Commun. 2012, 422 (1), 85-90.

(30) MacRae, C. A.; Peterson, R. T. Zebrafish as tools for drug discovery. Nat. Rev. Drug Discovery 2015, 14 (10), 721-731.

(31) Alfaro, J. M.; Prades, A.; del Carmen Ramos, M.; Peris, E.; Ripoll-Gómez, J.; Poyatos, M.; Burgos, J. S. Biomedical properties of a series of ruthenium-N-heterocyclic carbene complexes based on oxidant activity in vitro and assessment in vivo of biosafety in zebrafish embryos. Zebrafish 2010, 7 (1), 13-21.

(32) Lenis-Rojas, O. A.; Fernandes, A. R.; Roma-Rodrigues, C.; Baptista, P. V.; Marques, F.; Perez-Fernandez, D.; Guerra-Varela, J.; Sanchez, L.; Vazquez-Garcia, D.; Torres, M. L.; Fernandez, A.; Fernandez, J. J. Heteroleptic mononuclear compounds of ruthenium(II): synthesis, structural analyses, in vitro antitumor activity and in vivo toxicity on zebrafish embryos. Dalton Trans. 2016, 45 (47), 19127-19140.

(33) Tang, T. S.-M.; Leung, K.-K.; Louie, M.-W.; Liu, H.-W.; Cheng, S. H.; Lo, K. K.-W. Phosphorescent biscyclometallated iridium(III) ethylenediamine complexes functionalised with polar ester or carboxylate groups as bioimaging and visualisation reagents. Dalton Trans. 2015, 44 (11), 4945-4956.

(34) Li, S. P.-Y.; Lau, C. T.-S.; Louie, M.-W.; Lam, Y.-W.; Cheng, S. H.; Lo, K. K.-W. Mitochondria-targeting cyclometalated iridium(III)-PEG complexes with tunable photodynamic activity. Biomaterials 2013, 34 (30), 7519-7532.

(35) Liu, Z.; Habtemariam, A.; Pizarro, A. M.; Fletcher, S. A.; Kisova, A.; Vrana, O.; Salassa, L.; Bruijnincx, P. C. A.; Clarkson, G. J.; Brabec, V.; Sadler, P. J. Organometallic half-sandwich iridium anticancer complexes. J. Med. Chem. 2011, 54 (8), 3011-3026.

(36) Romero-Canelón, I.; Salassa, L.; Sadler, P. J. The contrasting activity of iodido versus chlorido ruthenium and osmium arene azoand imino-pyridine anticancer complexes: control of cell selectivity, cross-resistance, p53 dependence, and apoptosis pathway. J. Med. Chem. 2013, 56 (3), 1291-1300.

(37) Teis, D.; Huber, L. A. The odd couple: signal transduction and endocytosis. Cell. Mol. Life Sci. 2003, 60 (10), 2020-2033.

(38) Sanchez-Cano, C.; Romero-Canelón, I.; Yang, Y.; HandsPortman, I. J.; Bohic, S.; Cloetens, P.; Sadler, P. J. Synchrotron x-ray fluorescence nanoprobe reveals target sites for organo-osmium complex in human ovarian cancer cells. Chem. - Eur. J. 2017, 23 (11), 2512-2516.

(39) Alberts, D. S. Carboplatin versus cisplatin in ovarian cancer. Semin Oncol. 1995, 22 (5), 88-90.

(40) Nanayakkara, A. K.; Follit, C. A.; Chen, G.; Williams, N. S.; Vogel, P. D.; Wise, J. G. Targeted inhibitors of P-glycoprotein increase chemotherapeutic-induced mortality of multidrug resistant tumor cells. Sci. Rep. 2018, 8 (1), 967.

(41) Ozaki, T.; Nakagawara, A. Role of p53 in cell death and human cancers. Cancers 2011, 3 (1), 994-1013.

(42) Hileman, E. O.; Liu, J.; Albitar, M.; Keating, M. J.; Huang, P. Intrinsic oxidative stress in cancer cells: a biochemical basis for therapeutic selectivity. Cancer Chemother. Pharmacol. 2004, 53 (3), 209-219.
(43) Baumann, F.; Kaim, W.; Denninger, G.; Kümmerer, H.-J.; Fiedler, J. Widely separated reduction processes of abpy-coupled arene osmium(II) reaction centers (abpy $=2,2^{\circ}$-azobispyridine): stabilization of the radical intermediate and of the Os0 OsII state. Organometallics 2005, 24 (8), 1966-1973.

(44) Needham, R. J.; Sanchez-Cano, C.; Zhang, X.; RomeroCanelón, I.; Habtemariam, A.; Cooper, M. S.; Meszaros, L.; Clarkson, G. J.; Blower, P. J.; Sadler, P. J. In-Cell Activation of OrganoOsmium(II) Anticancer Complexes. Angew. Chem., Int. Ed. 2017, 56 (4), 1017-1020.

(45) Zobi, F.; Mood, B. B.; Wood, P. A.; Fabbiani, F. P. A.; Parsons, S.; Sadler, P. J. Tagging (arene)ruthenium(II) anticancer complexes with fluorescent labels. Eur. J. Inorg. Chem. 2007, 2007 (18), 27832796.

(46) Mugoni, V.; Camporeale, A.; Santoro, M. M. Analysis of oxidative stress in zebrafish embryos. J. Visualized Exp. 2014, No. 89, 51328.

(47) Rissone, A.; Candotti, F. Detection of reactive oxygen species using MitoSOX and CellROX in zebrafish. Bio-protocol 2016, 6 (19), 1941.

(48) Brosnan, M. E.; Brosnan, J. T. Formate: the neglected member of one-carbon metabolism. Annu. Rev. Nutr. 2016, 36 (1), 369-388.

(49) Lee, M. S.; Bonner, J. R.; Bernard, D. J.; Sanchez, E. L.; Sause, E. T.; Prentice, R. R.; Burgess, S. M.; Brody, L. C. Disruption of the folate pathway in zebrafish causes developmental defects. BMC Dev. Biol. 2012, 12, 12-24.

(50) Böhme, S.; Stärk, H.-J.; Kühnel, D.; Reemtsma, T. Exploring LA-ICP-MS as a quantitative imaging technique to study nanoparticle uptake in Daphnia magna and zebrafish (Danio rerio) embryos. Anal. Bioanal. Chem. 2015, 407 (18), 5477-5485.

(51) Ackerman, C. M.; Weber, P. K.; Xiao, T.; Thai, B.; Kuo, T. J.; Zhang, E.; Pett-Ridge, J.; Chang, C. J. Multimodal LA-ICP-MS and nanoSIMS imaging enables copper mapping within photoreceptor megamitochondria in a zebrafish model of Menkes disease. Metallomics 2018, 10 (3), 474-485.

(52) Bohme, S.; Baccaro, M.; Schmidt, M.; Potthoff, A.; Stark, H.-J.; Reemtsma, T.; Kuhnel, D. Metal uptake and distribution in the zebrafish (Danio rerio) embryo: differences between nanoparticles and metal ions. Environ. Sci.: Nano 2017, 4 (5), 1005-1015.

(53) van Rijt, S. H.; Romero-Canelon, I.; Fu, Y.; Shnyder, S. D.; Sadler, P. J. Potent organometallic osmium compounds induce mitochondria-mediated apoptosis and S-phase cell cycle arrest in A549 non-small cell lung cancer cells. Metallomics 2014, 6 (5), 10141022.

(54) Dougan, S. J.; Habtemariam, A.; McHale, S. E.; Parsons, S.; Sadler, P. J. Catalytic organometallic anticancer complexes. Proc. Natl. Acad. Sci. U. S. A. 2008, 105 (33), 11628-11633.

(55) Zamble, D. B.; Jacks, T.; Lippard, S. J. p53-dependent and -independent responses to cisplatin in mouse testicular teratocarcinoma cells. Proc. Natl. Acad. Sci. U. S. A. 1998, 95 (11), 6163-6168.

(56) Venzago, C.; Popp, M.; Kovac, J.; Kunkel, A. Pharmacopeial requirements for elemental impurities: a novel approach to the trace determination of osmium by oxidative pressure vessel sample digestion and measurement using inductively coupled plasma mass spectrometry (ICP-MS) after complexation and stabilisation. J. Anal. At. Spectrom. 2013, 28 (7), 1125-1129. 